\title{
Neuronal life or death linked to depression treatment: the interplay between drugs and their stress-related outcomes relate to single or combined drug therapies
}

\author{
Przemyslaw Solek ${ }^{1}$ (1) $\cdot$ Oliwia Koszla ${ }^{1,2}$. Jennifer Mytych ${ }^{1}$ (1) $\cdot$ Joanna Badura ${ }^{1} \cdot Z^{2}$ aneta Chelminiak ${ }^{1}$.

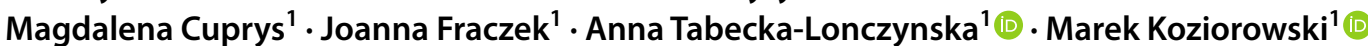

Published online: 5 July 2019

(c) The Author(s) 2019

\begin{abstract}
Depression is a serious medical condition, typically treated by antidepressants. Conventional monotherapy can be effective only in $60-80 \%$ of patients, thus modern psychiatry deals with the challenge of new methods development. At the same moment, interactions between antidepressants and the occurrence of potential side effects raise serious concerns, which are even more exacerbated by the lack of relevant data on exact molecular mechanisms. Therefore, the aims of the study were to provide up-to-date information on the relative mechanisms of action of single antidepressants and their combinations. In this study, we evaluated the effect of single and combined antidepressants administration on mouse hippocampal neurons after 48 and $96 \mathrm{~h}$ in terms of cellular and biochemical features in vitro. We show for the first time that co-treatment with amitriptyline/imipramine + fluoxetine initiates in cells adaptation mechanisms which allow cells to adjust to stress and finally exerts less toxic events than in cells treated with single antidepressants. Antidepressants treatment induces in neuronal cells oxidative and nitrosative stress, which leads to micronuclei and double-strand DNA brakes formation. At this point, two different mechanistic events are initiated in cells treated with single and combined antidepressants. Single antidepressants (amitriptyline, imipramine or fluoxetine) activate cell cycle arrest resulting in proliferation inhibition. On the other hand, treatment with combined antidepressants (amitriptyline/imipramine + fluoxetine) initiates p16-dependent cell cycle arrest, overexpression of telomere maintenance proteins and finally restoration of proliferation. In conclusion, our findings may pave the way to better understanding of the stress-related effects on neurons associated with mono- and combined therapy with antidepressants.
\end{abstract}

Keywords Depression $\cdot$ Neurons $\cdot$ Antidepressants $\cdot$ Amitriptyline $\cdot$ Imipramine $\cdot$ Fluoxetine

\section{Introduction}

According to the World Health Organization, depression is the most common mental disorder highly prevalent among millions of people across the world. It is also one of the main

Przemyslaw Solek

pp.solek@gmail.com; psolek@univ.rzeszow.pl

1 Department of Animal Physiology and Reproduction, Faculty of Biotechnology, University of Rzeszow, Werynia 502, 36-100 Kolbuszowa, Poland

2 Present Address: Department of Synthesis and Chemical Technology of Pharmaceutical Substances with Computer Modeling Lab, Faculty of Pharmacy with Division of Medical Analytics, Medical University of Lublin, Chodzki 4A, 20-093 Lublin, Poland types of affective disorders and refers to a wide range of mental, cognitive, physical and behavioral health problems having a destructive impact on quality of everyday life [1-3].

Drugs available on the present pharmaceutical market are divided into groups according to their chemical structure and mechanism of action $[4,5]$. Furthermore, antidepressants use is often associated with a long time administration, therefore their side effects and their wide range posses a significant risk [4, 6]. Also, their effectiveness is still questioned. It is now accepted that conventional monopharmacotherapy (with the use of single antidepressant) can be effective only in $60-80 \%$ of patients $[7,8]$. For this reason, development of new and definitely better drugs is undoubtedly a huge challenge for modern psychiatry [9]. Research suggest that for many people with major depression, one drug is not enough to deal with a comprehensive 
range of symptoms experienced by patients. In case of treatment failure, the alternative therapies can be applied. These include among others combined administration of antidepressants with improved clinical efficacy $[10,11]$. The use of combined therapy (the use of two or even more antidepressants with different mechanisms of action) has been already described in some papers [12-15]. Typically, during monopharmacotherapy patients are prescribed fluoxetine at a dosage $20-80 \mathrm{mg} /$ day, which gives steady-state plasma levels of $\sim 0.6-1 \mu \mathrm{M}$ after $2-4$ weeks of $60 \mathrm{mg} / \mathrm{day}$ [16]. Amitriptyline is usually prescribed $75-150 \mathrm{mg} /$ day, which corresponds to $0.18-0.5 \mu \mathrm{M}$ levels in plasma after 6 weeks of treatment [17]. In dual therapies, the doses can be lowered to $32.75 \mathrm{mg} /$ day of both drugs with no changes in the effectiveness of the treatment [13]. Amitriptyline and fluoxetine are often considered as drugs of choice due to their neuroprotective and anti-inflammatory effects [18]. At the same moment, combining compounds with two different mechanisms of pharmacological action that complement each other in terms of the therapy efficacy raises concerns about the interactions between these drugs and the occurrence of potential adverse drug reaction [10].

For better understanding of antidepressants side effects, it is crucial to become acquainted with molecular mechanisms underlying their toxicity. Some reports indicate that antidepressants posses cyto- and genotoxic properties. Elmorsy et al. presented that fluoxetine, sertaline and clomipramine treatment reduces cellular oxygen consumption rates, activities of the mitochondrial complexes I and II and triggers an increase of lactate production. Moreover, higher concentrations of antidepressants were linked with upregulation of pro-apoptotic caspases-3, 8 and 9 in response to global reactive oxygen species-mediated DNA damage in rat primary blood barrier endothelial cells [19]. Further detailed studies revealed that structural chromosomal abnormalities [20], as well as telomeres shortening, may be involved in antidepressants-induced neurotoxicity [21]. As cited, the data on antidepressant-mediated toxicity is still fragmentary and mostly deals with the effect of monotherapy on stress-related effects.

Therefore, the specific aims of this study were to provide up-to-date comparative analysis on the relative neurotoxicity mechanisms of individual antidepressants (amitriptyline, imipramine, fluoxetine-'single therapies') and their combinations (amitriptyline/fluoxetine, imipramine/ fluoxetine-'dual therapies'). Amitriptyline, imipramine and fluoxetine as considered to posses neuroprotective and antiinflammatory characteristics were chosen for analyses. The study was designed to cover therapeutic, hyper-therapeutic and overdose concentrations and allowed us to determine the molecular mechanisms that drive drug-induced neurotoxicity within a 48 and $96 \mathrm{~h}$ time-frame.

\section{Materials and methods}

\section{General}

All reagents were purchased from Sigma-Aldrich (Poland), BioShop (Canada), Thermo Fisher Scientific (USA) or Chempur (Poland), had analytical grade purity and were used as obtained unless otherwise stated. All reactions, except cell culture, were carried out under normal atmospheric conditions at room temperature. All presented photos were not subjected to any image processing and represent raw data.

\section{Antibodies}

Antibodies used were: anti- $\beta$-actin (\#PA1-16889), anti-p16 (\#PA5-16639), anti-p21 (\#PA5-701151), anti-p27 (\#PA513254), anti-p53 (\#700439), anti-phospho-NF-кB (\#PA537658), anti-NuMA (\#PA132451), anti-calnexin (\#MA3027) (Thermo Fisher Scientific), anti-Bcl-2 (\#sc-7382) (Santa Cruz), anti-active caspase 3 (\#NB100-56113) (Novus Biologicals), anti- $\gamma \mathrm{H} 2 \mathrm{AX}$ (\#CS208203) (Merck Millipore). Secondary HRP-conjugated: anti-mouse (\#A9044) and antirabbit (\#A0545) (Sigma).

\section{Cell culture conditions}

The mouse hippocampal neuronal cells, HT-22, were purchased from Thermo Fisher Scientific, USA and routinely maintained in originally formulated Dulbecco's modified Eagle's medium (DMEM, Corning, USA) with high glucose $(4.5 \mathrm{~g} / \mathrm{l})$ and sodium pyruvate $(1 \mathrm{mM})$. The medium was supplemented with $10 \%$ heat-inactivated Fetal Bovine Serum (FBS, Biowest, France), 100 units $/ \mathrm{ml}$ penicillin, $100 \mu \mathrm{g} / \mathrm{ml}$ streptomycin and $29.2 \mathrm{mg} / \mathrm{ml} \mathrm{L-glutamine.} \mathrm{Neu-}$ ronal cells were kept in a humidified $\mathrm{CO}_{2}$ incubator (New Brunswick Galaxy 170R, Thermo Fisher Scientific) at $37^{\circ} \mathrm{C}$ with a mix gas containing $5 \% \mathrm{CO}_{2}$ environment to maintain physiological pH. HT-22 were passaged every 3 days at $90 \%$ confluence by trypsinization with $0.25 \%$ trypsin/ $0.02 \%$ EDTA (Thermo Fisher Scientific, USA). For all procedures, cells were seeded in a constant density of $3.0 \times 10^{3} / \mathrm{cm}^{2} 24 \mathrm{~h}$ before antidepressants treatment.

\section{Antidepressants treatment}

The antidepressant drugs: (1) amitriptyline hydrochloride, (2) imipramine hydrochloride, (3) fluoxetine hydrochloride were purchased from Sigma-Aldrich and were dissolved in dimethyl sulfoxide (DMSO) to a $100 \mathrm{mM}$ stock solution 
according to characteristic solubility. The drugs stock solutions were diluted in complete DMEM immediately before use and added to cells for 48 and $96 \mathrm{~h}$.

\section{MTT assay}

The MTT colorimetric method of cell proliferation and cytotoxicity determination was performed for the measurement of cell growth in response to antidepressants treatment. HT-22 cell cultures were prepared in 96-well format plates. The MTT stock solution was prepared in a physiologically balanced solution $(1 \times$ PBS $)$ and added to each well at a final concentration of $5 \mathrm{mg} / \mathrm{ml}$. After $4 \mathrm{~h}$ incubation at $37^{\circ} \mathrm{C}$ in culture hood, the formazan crystals were dissolved with DMSO and the absorbance was measured at $590 \mathrm{~nm}$ (absorbance) and $620 \mathrm{~nm}$ (reference) wavelengths using PerkinElmer Victor X4 2030 microplate reader. The results are presented as \%, while untreated CTRL cells were considered as $100 \%$. $\mathrm{IC}_{10}, \mathrm{IC}_{25}, \mathrm{IC}_{50}, \mathrm{IC}_{75}$ and $\mathrm{IC}_{90}$ values were calculated by fitting linear regression equation, which was best suitable.

\section{Alterations in cellular morphology}

We evaluated alterations in cell morphology in both, antidepressants-treated and control HT-22 cells after 48 and $96 \mathrm{~h}$ using an inverted light microscope Zeiss Axiovert $40 \mathrm{CFL}$ equipped with a Zeiss AxioCam MRm3 camera (Carl Zeiss, Germany). Digital images were captured using phase contrast and AxioVs40 V 4.8.1.0 software.

\section{Determination of oxidative and nitrosative stress parameters}

Measurement of intracellular superoxide radical anion was evaluated using fluorogenic DHE probe (dihydroethidium; at final concentration $5 \mu \mathrm{M}$, Thermo Fisher Scientific), nitric oxide (NO) production was measured using DAF-FM probe (4-amino-5 methyloamino-2',7'-difluorofluorescein diacetate: at final concentration $5 \mu \mathrm{M}$, Cayman Chemical) while reduced glutathione levels were estimated using robust intracellular thiol probe for GSH (Thiol tracker violet: at final concentration $5 \mu \mathrm{M}$, Thermo Fisher Scientific). Digital images and quantifications were performed using InCell Analyzer 2000 and presented as relative fluorescence units (RFU). A minimum of 1000 cells were counted in each sample.

\section{ATP-Iuminescence measurements}

Total ATP cellular levels were detected using ATP-luminescence system (PerkinElmer, USA) for the quantitative evaluation of proliferation and antidepressants-mediated cytotoxicity of cultured HT-22 cells, according to the manufacturer's instructions. In brief, the lyophilized substrate solution vial was resolved in adequate volume of substrate buffer solution. Then, mammalian cell lysis solution was added and cells were incubated for $5 \mathrm{~min}$ in an orbital shaker. After incubation, the substrate solution was added to each well and mixed again in an orbital shaker. The luminescence was measured at darkadapted plate using PerkinElmer Victor X4 2030 microplate reader. The values were given as relative values to control cells.

\section{Analysis of cell cycle profile and micronuclei formation}

The cell cycle profile analysis by DNA content measurement was performed using two fluorescent dyes (nuclei: DAPI at final concentration $1 \mu \mathrm{g} / \mathrm{ml}$; cell cytoplasm: Calcein-AM at final concentration $0.3 \mu \mathrm{g} / \mathrm{ml}$ ). Images were captured using InCell Analyzer 2000 and the output was processed by the ImageJ software with the DNA cell cycle plug-in. Cell cycle phases in a given cell population were presented as \% of cells in G0/G1, S and G2/M phases (cell cycle distribution) or as $\%$ of micronuclei positive cells (micronuclei formation). A minimum of 1000 cells were counted in each sample.

\section{Immunofluorescence staining of $\gamma \mathrm{H} 2 \mathrm{AX}$}

The phosphorylation status of $\gamma \mathrm{H} 2 \mathrm{AX}$ as a biomarker of DNA damage was detected using immunostaining standard protocol. In short, cells were fixed in 4\% paraformaldehyde, permeabilized in PBS containing 0.25\% Triton X-100, blocked with $1 \%$ BSA and then incubated with the primary antibody prepared in $1 \%$ BSA in PBST overnight at $4{ }^{\circ} \mathrm{C}$. Next, the cells were washed three times in PBS (5 min each wash) and nuclei were visualized with Hoechst 33258. Fluorescent images were captured using InCell Analyzer 2000 and ImageJ software was applied for $\gamma \mathrm{H} 2 \mathrm{AX}$ quantification.

\section{Western blot}

Total protein extracts were prepared and Western Blot method was carried out as previously described in Solek et al with minor modifications [22]. Briefly, $30 \mu \mathrm{g}$ of whole cell protein lysates were separated by size using \% SDSPAGE electrophoresis. After electrophoresis, the separated proteins were electroblotted onto a methanol-activated polyvinylidene difluoride membranes (PVDF, Thermo Fisher Scientific) and blocked in 1\% BSA for $1 \mathrm{~h}$ to prevent nonspecific binding of the antibody probes. The proteins were then complexed with specific primary and secondary HRP-conjugated antibodies. Detection and localization of target proteins were performed using ECL western blotting substrate (BioRad, USA) and Fusion Fx7 system (Viber 
Lourant) according to the provided instructions. The relative protein expression levels were normalized to $\beta$-actin (GelQuantNET software).

\section{Presentation of results and statistical analysis}

Adobe Photoshop CC software was used to process images and to design all figures. Data shown represent the means \pm standard deviation. The experiments were repeated three times with at least $n=3$ per treatment condition. Statistical multiple comparisons were performed using GraphPad Prism ver. 6.0 and the data were assessed with one-way
ANOVA followed by Dunnett post hoc test. A p-value of $<0.05$ was considered statistically significant between groups and are displayed as: $*^{/ \wedge} \mathrm{p}<0.05 ; * * / \wedge \mathrm{p}<0.01$; $* * * / \wedge \wedge \wedge<0.001$. Asterisks $(*)$ indicate the comparison between CTRL (non-treated) and antidepressants-treated cells while carets $\left({ }^{\wedge}\right)$ indicate the comparison between the same drugs in different periods ( $48 \mathrm{~h}, 96 \mathrm{~h})$.
(A)<smiles>CNCCC=C1c2ccccc2CCc2ccccc21</smiles>

(D)<smiles>CNCCCN1c2ccccc2CCc2ccccc21</smiles>

(G)<smiles>CNCCC(Oc1ccc(C(F)(F)F)cc1)c1ccccc1</smiles>

(J)

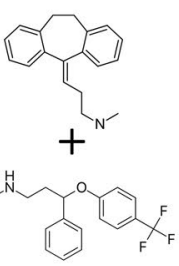

(M)

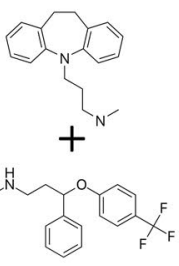

(B)

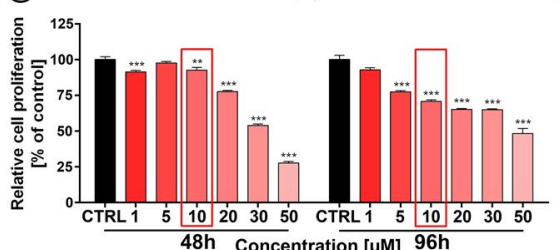

(E)

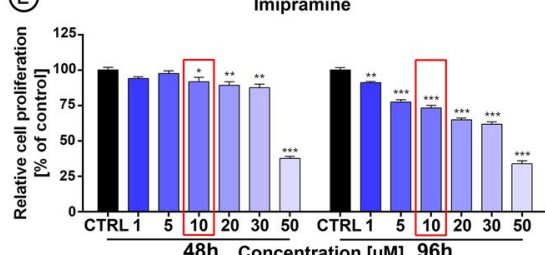

(4)

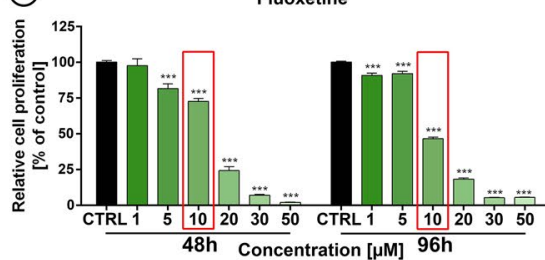

(K)
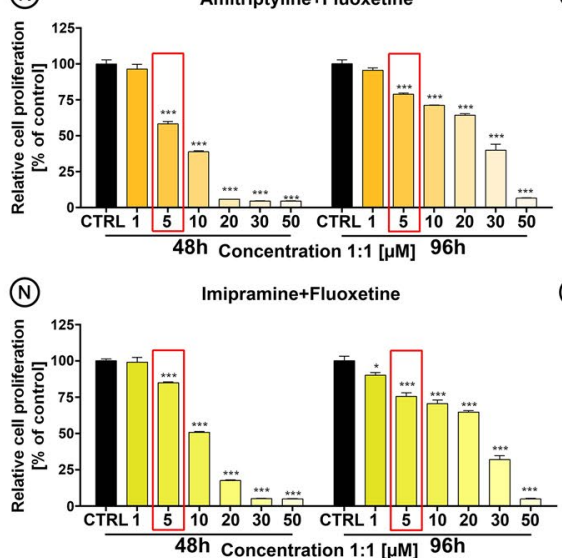

(C)

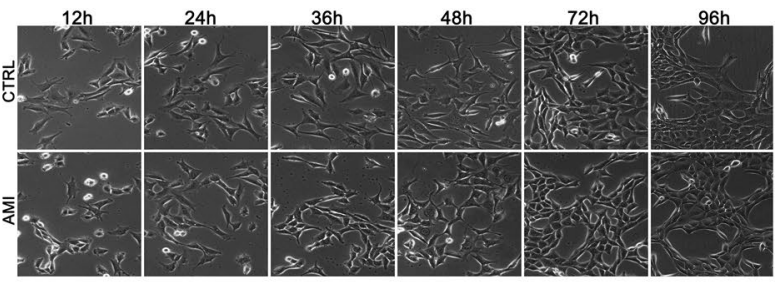

(F)

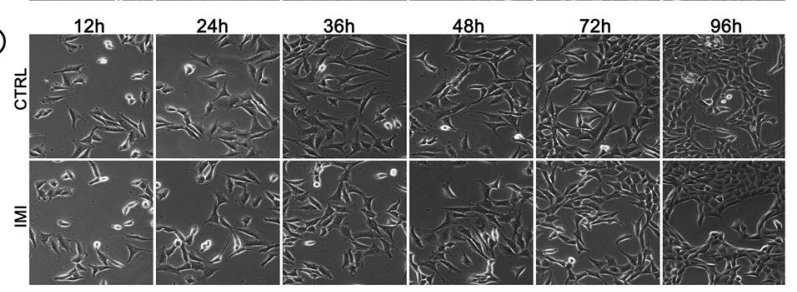

(1)

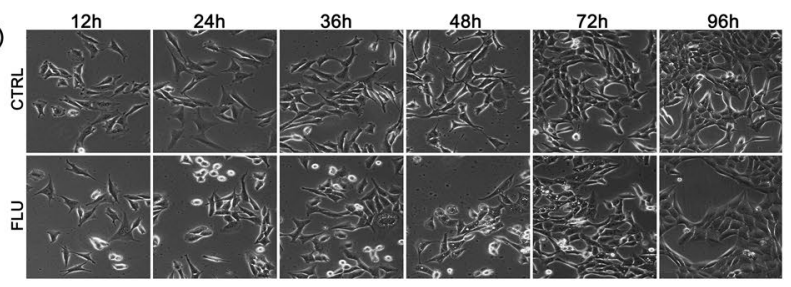

(L)

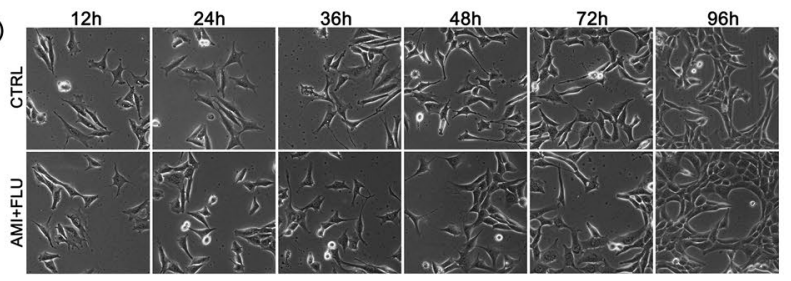

()

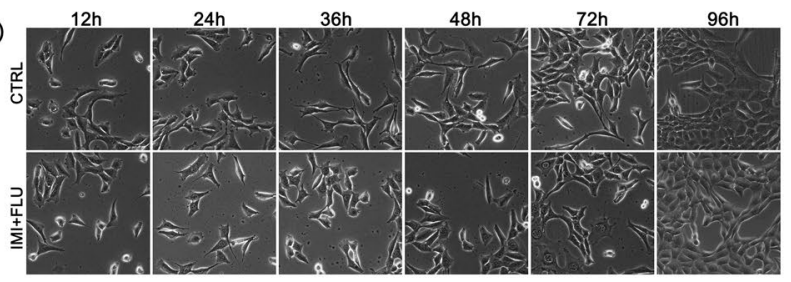

Fig. 1 Antidepressants-mediated effects in mouse hippocampal neurons (HT-22 cells). Chemical structure of amitriptyline (a), imipramine (d), fluoxetine (g), amitriptyline + fluoxetine (j), imipramine + fluoxetine (m). Cells were treated for 48 and $96 \mathrm{~h}$ with wide range of antidepressants concentrations and MTT assay was performed $(\mathbf{b}, \mathbf{e}, \mathbf{h}, \mathbf{k}, \mathbf{n})$ to chose one concentration for further studies and then the effects of single $10 \mu \mathrm{M}$ and combined $5+5 \mu \mathrm{M}$ antidepressants on morphological characteristics $(\mathbf{c}, \mathbf{f}, \mathbf{i}, \mathbf{l}, \mathbf{o})$ were evaluated. Magnification of the objective lens $\times 10$. Bars indicate SD,

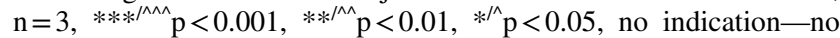
statistical significance (one-way ANOVA and Dunnett's a posteriori test) 


\section{Results}

\section{Antidepressants regulate the neuronal mitochondrial activity of mouse hippocampal cells}

At the beginning, the HT-22 cells were treated with amitriptyline (AMI) (Fig. 1a), imipramine (IMI) (Fig. 1d) and fluoxetine (FLU) (Fig. 1g) or co-treated with AMI+ FLU (Fig. 1j) and IMI + FLU (Fig. 1m) with a wide concentrations range $(1-50 \mu \mathrm{M})$. Then, the in vitro cytotoxicity after 48 and $96 \mathrm{~h}$ based on MTT assay was evaluated. We found that relative cell proliferation was reduced after antidepressants treatment in a concentration-dependent manner. The differences were less pronounced after $96 \mathrm{~h}$ than after $48 \mathrm{~h}$ in any experimental set, except FLU (Fig. 1b, e, h, k, n). ICs values for the observed effects generated via regression analyses are presented in Table 1.

Based on cytotoxicity results, we chose one concentration of antidepressants for further research (marked in the red frames), due to the fact that high, toxic concentrations are not clinically applicable.

\section{Effects of antidepressant treatment on cell morphology}

To investigate the effects of selected antidepressants on cell morphology, we treated mouse hippocampal cells for a period of $96 \mathrm{~h}$. Single ( $10 \mu \mathrm{M}$ concentration) or combined (5 $\mu \mathrm{M}+5 \mu \mathrm{M}$ concentration) treatment did not significantly alter the cell morphology. Cells were characterized by a typical neuron-like morphology, elongated shape, with a single nucleus and equally distributed and granular cytoplasm (Fig. 1c, f, 1, o). Although no consistent morphologic abnormalities in almost all treated sets were observed, FLUtreated cells were altered in their growth characteristics. We observed round and shrunk cells with smooth plasma membrane as well as vacuolization and partial detachment from the substrate (Fig. 1i).

\section{Oxidative and nitrosative stress versus antioxidant defense}

Next, we decided to evaluate what is the cause of cell proliferation reduction, therefore the parameters of oxidative and nitrosative stress were controlled. Indeed, drugs caused an increase in the production of nitric oxide in each experimental set analyzed. Furthermore, we find out that antidepressants activated defense mechanisms against free radicals by thiol overproduction after $48 \mathrm{~h}$, but not after $96 \mathrm{~h}$. Interestingly, the superoxide level remained at the control level after $48 \mathrm{~h}$, but we observed an unambiguous decline in the superoxide production after $96 \mathrm{~h}$ (again as before-except FLU) (Fig. 2a-e).

\section{Mitochondrial response to nitrosative and oxidative imbalance}

In the view of results above, we investigated the relationship between alterations in the oxidative and nitrosative imbalance and mitochondrial function. We noted moderately reduced intracellular ATP levels promoted by mitochondria damage (results not statistically significant). The effect was even more pronounced after $96 \mathrm{~h}$ as compared with control. In addition, the most significant declines were observed in the case of cells treated with FLU for both, 48 and $96 \mathrm{~h}$ (Fig. 3a).

\section{Interaction between DNA and antidepressants}

Further, in order to explain these toxicities mechanisms, we studied the relationship between selected concentrations of the antidepressants and the cell cycle progression, micronuclei formation and DNA damage. We observed that antidepressant treatment induced statistically
Table 1 ICs $(\mu \mathrm{M})$ of antidepressants (ADs) for HT-22 cells

\begin{tabular}{|c|c|c|c|c|c|c|}
\hline ADs & $\begin{array}{l}\text { Time of } \\
\text { exposure } \\
\text { (h) }\end{array}$ & $\mathrm{IC}_{90}$ & $\mathrm{IC}_{75}$ & $\mathrm{IC}_{50}$ & $\mathrm{IC}_{25}$ & $\mathrm{IC}_{10}$ \\
\hline \multirow[t]{2}{*}{ AMI } & 48 & $63.33 \pm 5.34$ & $52.93 \pm 4.64$ & $35.59 \pm 3.48$ & $18.25 \pm 2.34$ & $7.85 \pm 1.69$ \\
\hline & 96 & $94.20 \pm 21.89$ & $76.35 \pm 18.50$ & $46.59 \pm 13.01$ & $16.82 \pm 8.05$ & $1.03 \pm 5.94$ \\
\hline \multirow[t]{2}{*}{ IMI } & 48 & $88.83 \pm 9.47$ & $74.49 \pm 8.18$ & $50.59 \pm 6.14$ & $26.68 \pm 4.52$ & $12.34 \pm 3.95$ \\
\hline & 96 & $72.02 \pm 9.59$ & $58.62 \pm 8.17$ & $36.28 \pm 5.93$ & $13.94 \pm 4.08$ & $1.03 \pm 3.43$ \\
\hline \multirow[t]{2}{*}{ FLU } & 48 & $37.26 \pm 1.93$ & $30.33 \pm 3.08$ & $18.80 \pm 2.44$ & $7.27 \pm 2.86$ & $0.34 \pm 3.19$ \\
\hline & 96 & $36.57 \pm 1.25$ & $29.28 \pm 1.25$ & $17.14 \pm 1.30$ & $4.99 \pm 1.42$ & $2.29 \pm 1.51$ \\
\hline \multirow[t]{2}{*}{ AMI + FLU [1:1] } & 48 & $34.29 \pm 3.64$ & $26.49 \pm 3.26$ & $13.50 \pm 2.69$ & $0.51 \pm 2.26$ & $0.16 \pm 2.09$ \\
\hline & 96 & $47.96 \pm 5.70$ & $39.47 \pm 5.28$ & $25.32 \pm 4.59$ & $11.16 \pm 3.93$ & $1.03 \pm 3.56$ \\
\hline \multirow[t]{2}{*}{ IMI + FLU [1:1] } & 48 & $34.47 \pm 1.64$ & $29.33 \pm 1.39$ & $17.45 \pm 0.98$ & $5.56 \pm 0.67$ & $1.57 \pm 0.58$ \\
\hline & 96 & $47.62 \pm 6.48$ & $39.20 \pm 6.14$ & $25.17 \pm 5.64$ & $11.14 \pm 5.20$ & $1.03 \pm 4.98$ \\
\hline
\end{tabular}



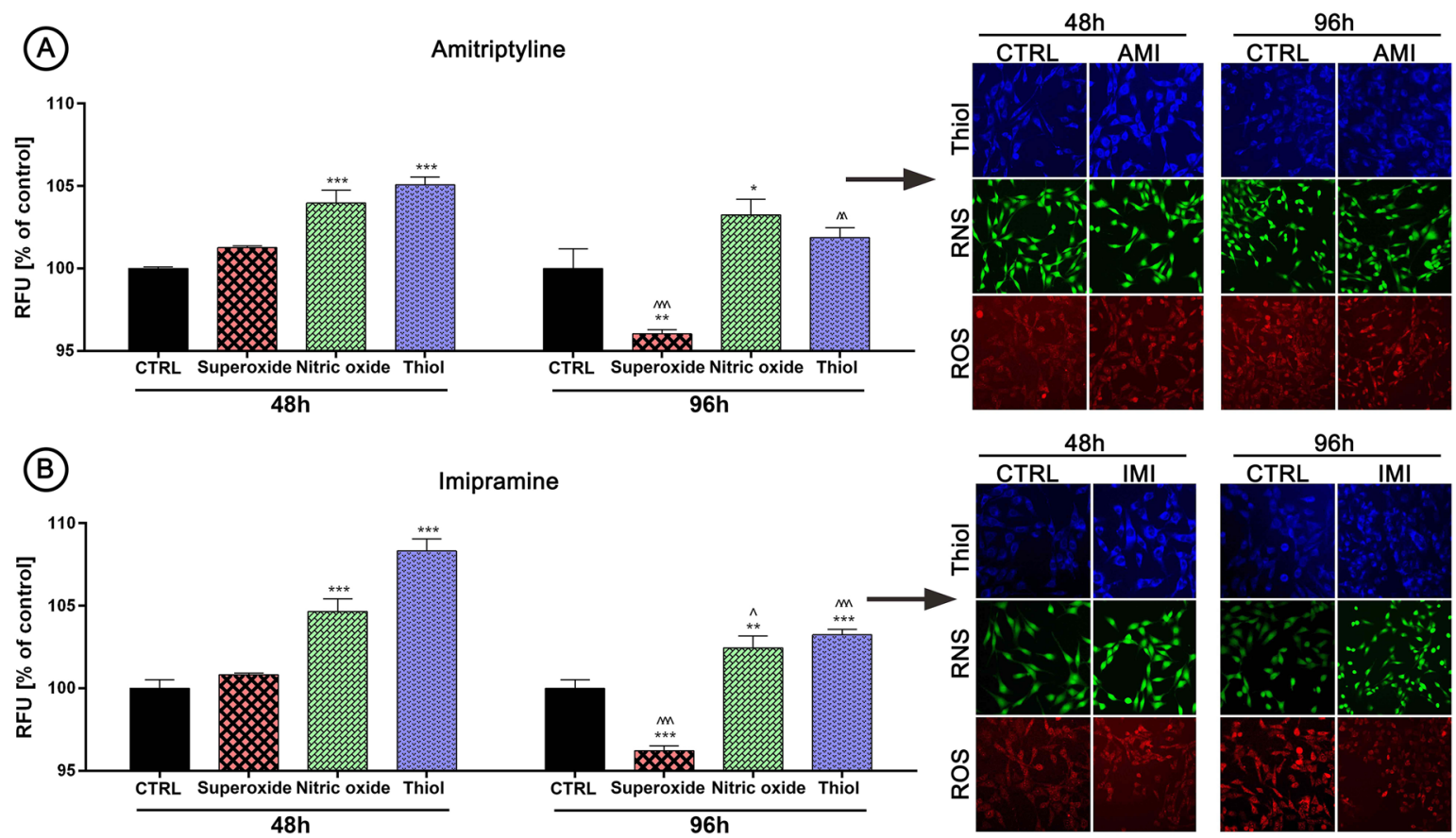

(C)

Fluoxetine
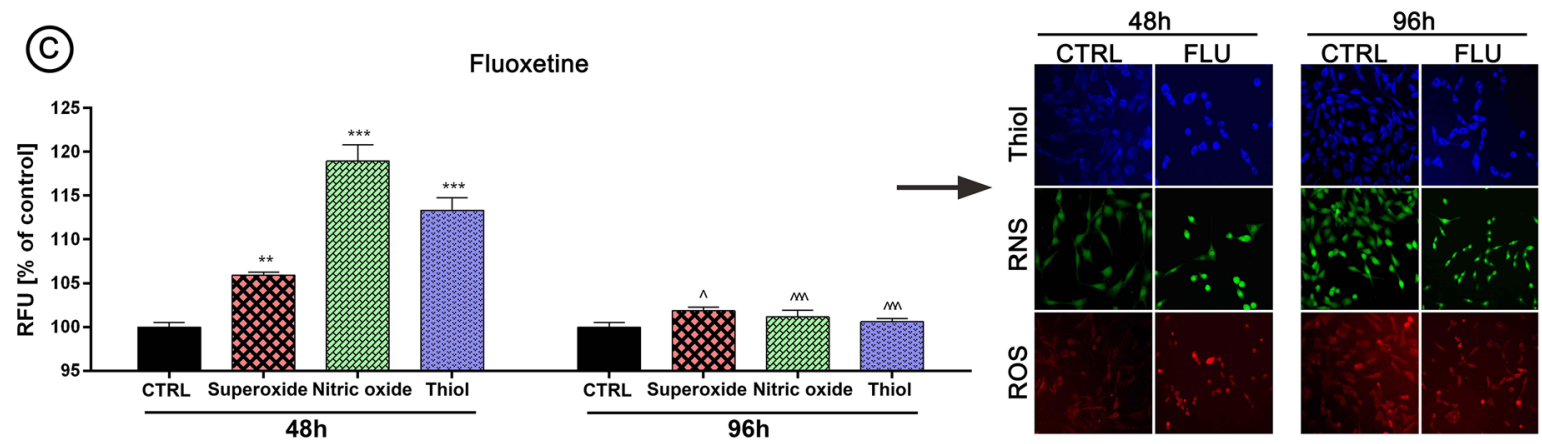

(D)

Amitriptyline+Fluoxetine
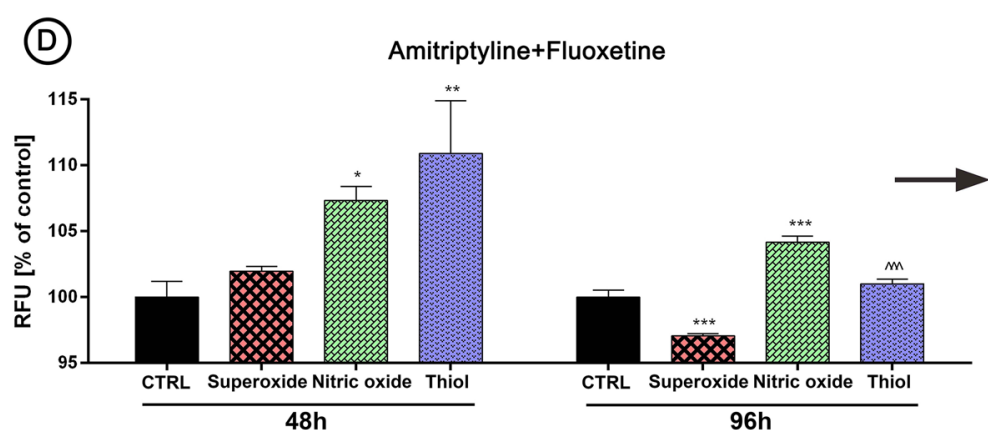

(E)

Imipramine+Fluoxetine

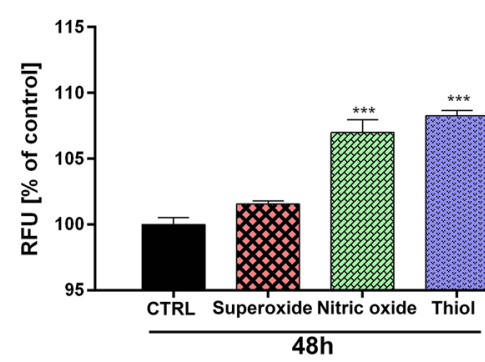

$48 \mathrm{~h}$

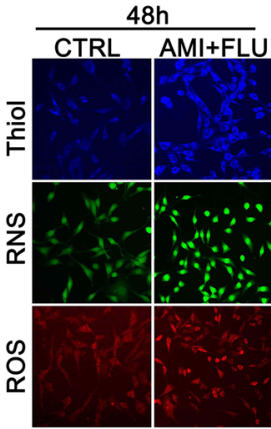

$\frac{96 \mathrm{~h}}{\text { CTRL AMI+FLU }}$

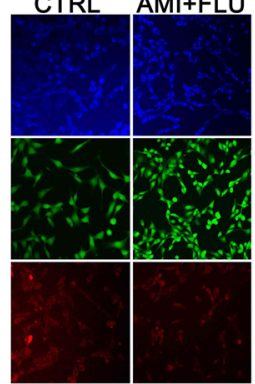

96h

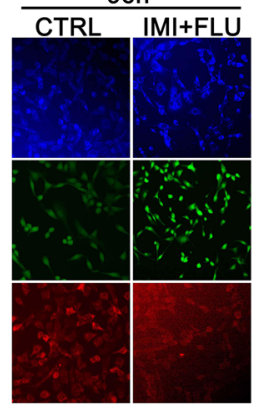


4Fig. 2 Antidepressants-mediated effects on oxidative/nitrosative stress and antioxidant defense. HT-22 cells were treated for 48 and $96 \mathrm{~h}$ and the effects of antidepressants on superoxide, nitric oxide and thiol production (a-e) were evaluated. Red fluorescence-dihydroethidium (ROS), green-4-amino-5-methylamino-2',7'-difluorofluorescein diacetate (NO), blue fluorescence-Thiol Tracker (Thiol). Magnification of the objective lens $\times 10$. Bars indicate SD, $n=3$,

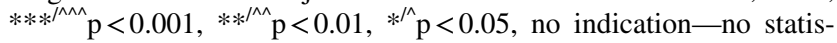
tical significance (one-way ANOVA and Dunnett's a posteriori test) (Color figure online)

significant reduction in the $\mathrm{G} 2 / \mathrm{M}$ or $\mathrm{S}$ cell cycle phase cell populations in all experimental sets after $48 \mathrm{~h}$ and the effect remained stable even after $96 \mathrm{~h}$. Moreover, four antidepressants sets (except AMI) displayed similar increases in G0/G1 phase cell number (Fig. 3b). In turn, antidepressants promoted DNA damage response in all cell lines examined by an increase in the number of cells with micronucleus frequency correlated with DNA double-strand breaks (DSBs). Again, the differences were

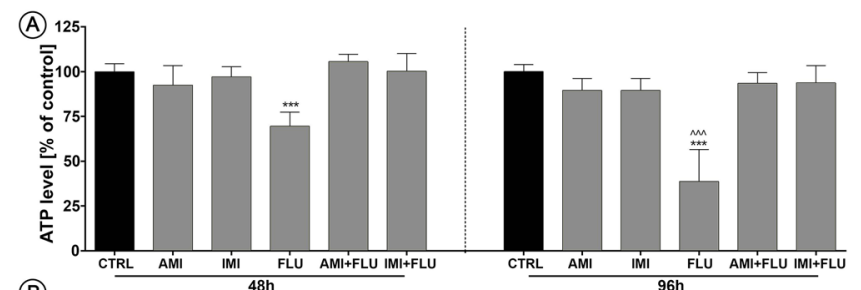

(B)
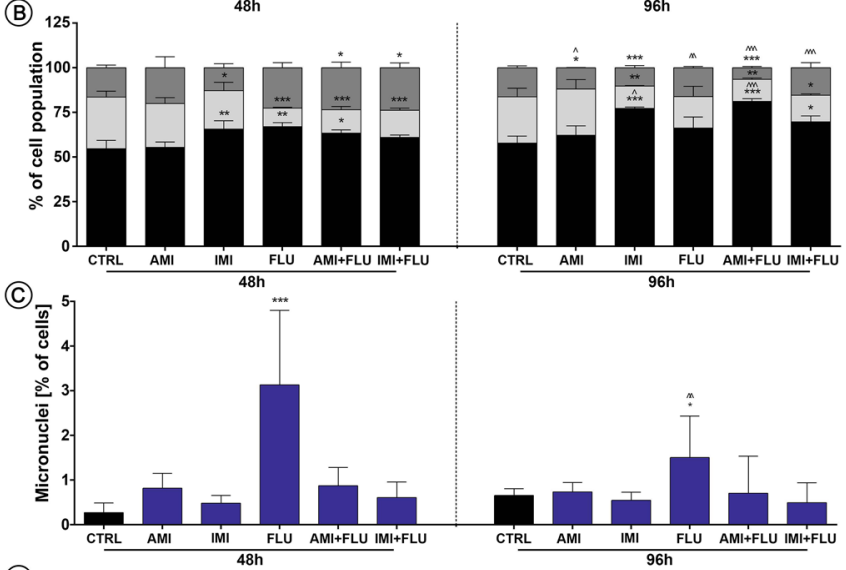

(D)

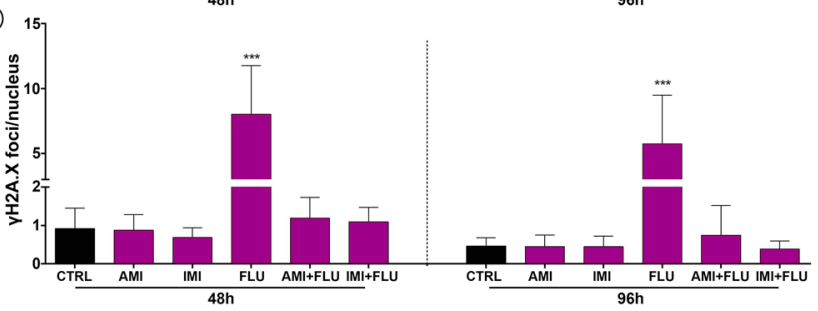

Fig. 3 Stress-related effects of antidepressants on cellular and biochemical features. Mouse hippocampal neurons were treated for 48 and $96 \mathrm{~h}$ and then the effects of antidepressants on ATP generation (a), cell cycle progression (b), micronuclei generation (c), $\gamma \mathrm{H} 2 \mathrm{AX}$ formation (d) were evaluated. Representative images of micronu-

less pronounced after 96 hours when compared to $48 \mathrm{~h}$ (Fig. 3c-f).

\section{Cell-signaling pathways activation and biochemical response to antidepressants}

Finally, we wanted to elucidate the molecular mechanisms underlying the toxic effects of antidepressants (Fig. 4a). Generally, antidepressants treatment did not activate redox-sensitive transcription factor (as assessed by the evaluation of its phosphorylation status) NF- $\kappa \mathrm{B}$ (Fig. 4b). In turn, the expression pattern of cell cycle regulatory proteins was affected. We noted up-regulated expression of DNA damage-associated protein p16 and p27 after FLU treatment (Fig. 4c, e) concomitant with the constant level of p21 and p53 (independent signaling pathways) (Fig. 4d, f). Based on these findings, we also focused our attention on proteins implicated in telomere length protection. Similarly, we did not detect significant

(E)
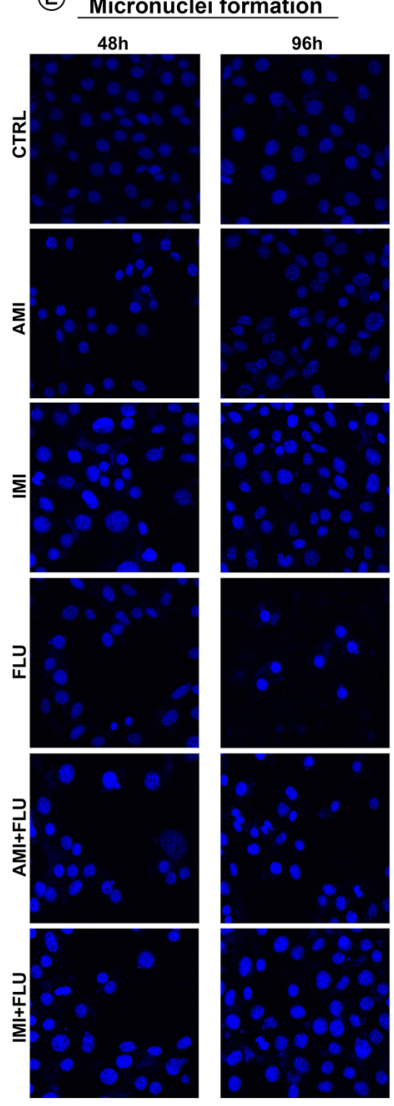
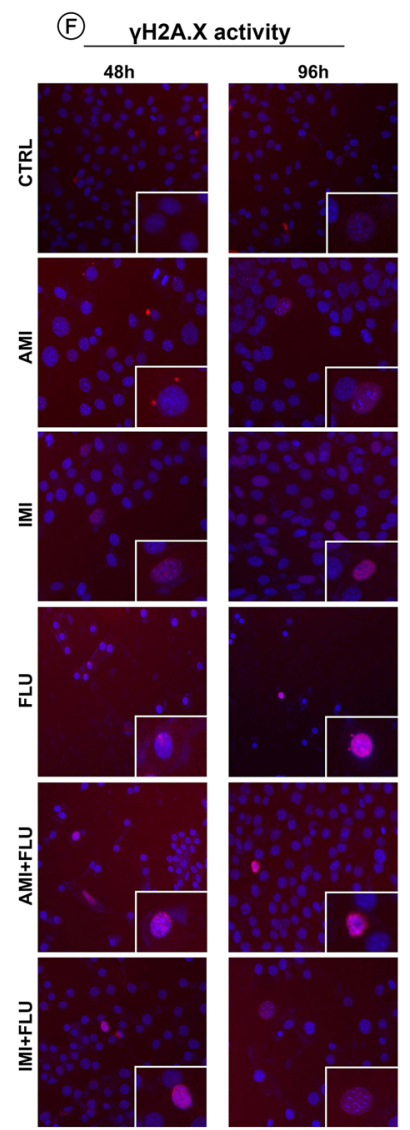

clei formation (e) and $\gamma \mathrm{H} 2 \mathrm{AX}$ activity (f) are shown. Blue fluorescence-Hoechst 33342, red-Texas Red. Magnification of the objective lens $\times 10$. Bars indicate SD, $\mathrm{n}=3, * * *^{\wedge \wedge \wedge} \mathrm{p}<0.001, * *{ }^{/ \wedge} \mathrm{p}<0.01$, $*^{/ \wedge} \mathrm{p}<0.05$, no indication-no statistical significance (one-way ANOVA and Dunnett's a posteriori test) (Color figure online) 

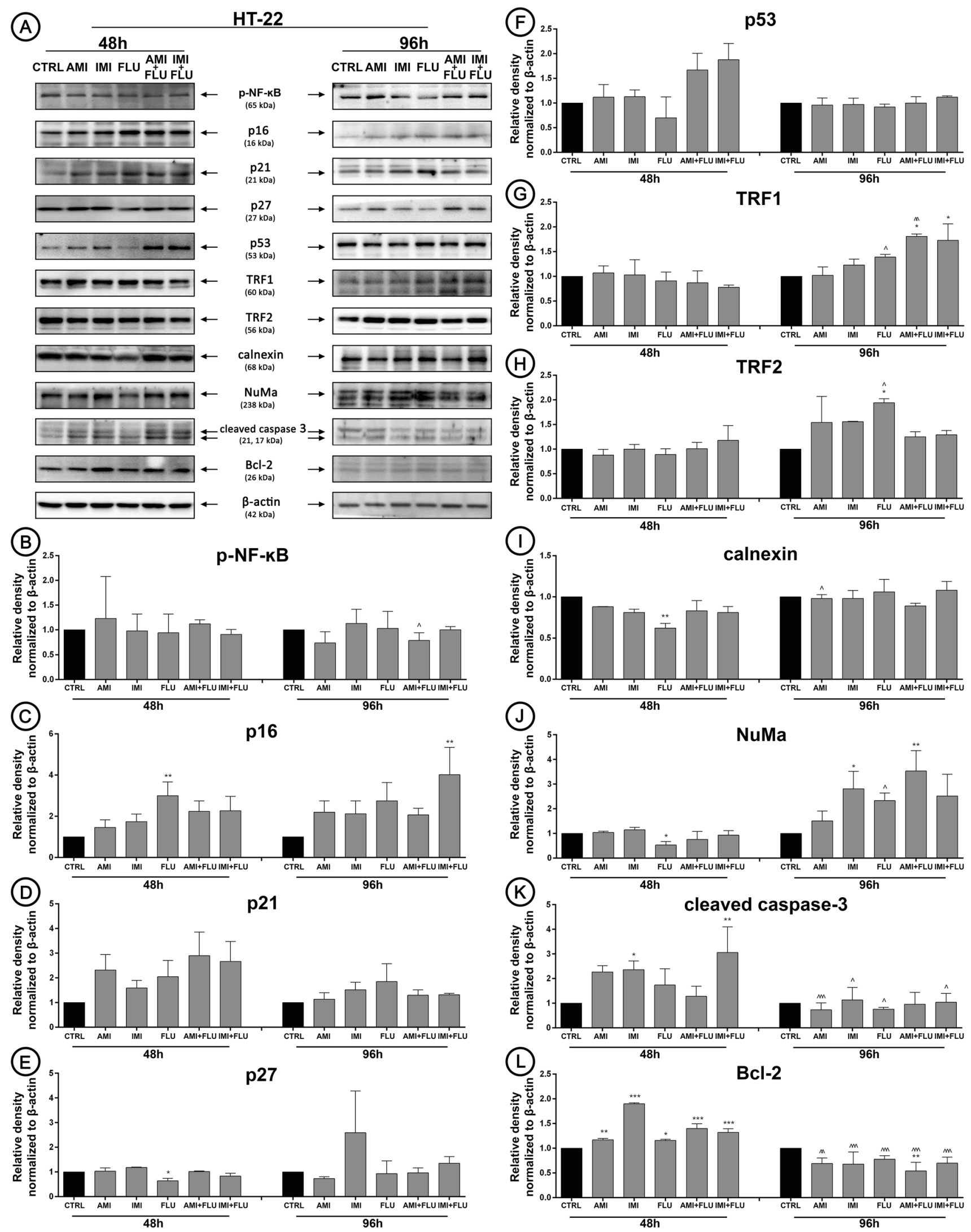
4Fig. 4 Antidepressants-mediated effect on cellular protein content. HT-22 cells were treated with antidepressants for 48 and $96 \mathrm{~h}$ and densitometry analysis of NF-kB (b), p16 (c), p21 (d), p27 (e), p53 (f), TRF1 (g), TRF2 (h), calnexin (i), NuMa (j), cleaved caspase 3 (k), Bcl-2 (l) was evaluated. Representative Western Blots are presented (a). Bars indicate $\mathrm{SD}, \mathrm{n}=3, * * *^{\wedge \wedge \wedge} \mathrm{p}<0.001, * *^{/ \wedge} \mathrm{p}<0.01$, $* / \wedge p 0.05$, no indication-no statistical significance (one-way ANOVA and Dunnett's a posteriori test)

changes in TRF1 and TRF2 after $48 \mathrm{~h}$ treatment, but interestingly, only FLU treatment resulted in upregulation of both proteins synthesis after 96 h (Fig. 4g, h). Continuing, in the case of FLU ( $48 \mathrm{~h}$ treatment), we observed downregulation of protein required for efficient folding of newly glycoproteins (calnexin) and protein essential for the formation of the mitotic spindle (NuMa) (Fig. 4i, j). Moreover, we confirmed activation of apoptotic cell death pathway in response to unrepairable DNA damage. We certainly confirmed that antidepressants treatment resulted in simultaneous upregulation of active caspase 3 and Bcl-2 after $48 \mathrm{~h}$, while $96 \mathrm{~h}$ incubation caused active caspase 3-dependent Bcl-2 decrease (Fig. 4k, 1).

\section{Discussion}

Our study was designed to compare the possible toxic effects of single and dual antidepressants used in therapeutic, hyper-therapeutic and overdose concentrations after 48-96 h exposures.

In general, firstly we demonstrated a clearly concentration-dependent relationship between the concentration of antidepressants and decrease of cell metabolic activity what is in agreement with previous reports [23-26]. Here, we additionally provide evidence that the decrease in the relative cell proliferation in cells treated for $96 \mathrm{~h}$ is less pronounced than in cells treated for $48 \mathrm{~h}$. Also, cells treated with combination of antidepressants better activate adaptation and repair mechanisms, what results in a significant acceleration of their growth rate when compared to cells treated with single antidepressants. The other authors suggest that a significant number of cells change characteristics in morphological shape and detach from the bottom of the culture flask at high drug concentrations which may indicate apoptosis [27, 28]. Interestingly in our research, only FLU exposure led to progressive morphological changes. However, we believe that morphological evaluation is questionable to draw far-reaching conclusions about the apoptosis, which is why we decided to carry out further studies to clarify the precise mechanisms of this process. Thus, in the next step, we were wondering what observed changes in metabolic activity could actually result from. This could be to due to initiation of oxidative and nitrosative stress, which in turn can directly or indirectly cause lipids, proteins and DNA damage [29]. As excepted, we observed a slight increase in the total ROS pool after $48 \mathrm{~h}$, while longer incubation resulted in a significant decrease, probably due to the activation of enzymatic mechanisms of cell protection. Our results are consistent with other authors [30-32]. Further, we observed a significant increase in NO after 48 and $96 \mathrm{~h}$ incubation, similarly to others [33-37]. Taken together these data, we suppose that high concentration of RNS is perhaps responsible for further cellular and molecular events that we observed later. Interesting is fact, that observed effect at this point was comparable between cells treated with single and combined antidepressants.

Consequently, exposure to oxidative and nitrosative stress may be sufficient to impair ATP production, increase mitochondrial membrane permeability and further alter functions of mitochondria. Indeed, in this study, we noted a decrease in ATP after $48 \mathrm{~h}$ which was even more pronounced after $96 \mathrm{~h}$ in cells treated with single antidepressant, fluoxetine. At the same time, the combination of fluoxetine with amitriptyline or imipramine did not cause similar effects. Others also reported that antidepressants lower ATP production and inhibit mitochondrial complex activity which is essential for reuptake of $\mathrm{Ca}^{2+}$ into the endoplasmic reticulum [38, 39]. ATP reduction was accompanied by decrease in $\mathrm{G} 2 / \mathrm{M}$ or $\mathrm{S}$ cell cycle phase cell populations with simultaneous increase in G0/ G1 phase cell number. At the same time, the pool of cells in $\mathrm{G} 0 / \mathrm{G} 1$ phase in cells treated with combination of antidepressants for $96 \mathrm{~h}$ increased when compared to $48 \mathrm{~h}$. The same phenomenon was not observed in cells treated with single antidepressants. This strongly suggests that cells treated with dual antidepressants activated mechanisms crucial for cellular repair and adaptation. The fact is that the cell cycle arrest at any of the checkpoint is thought to provide the cells time to repair the critical damage before DNA replication [40]. We observed an increase in micronuclei frequency correlated with DNA double-strand breaks after ADs treatment. Interesting fact is that these incidents were observed in cells treated with fluoxetine but not in cells treated with fluoxetine with amitriptyline or imipramine. Also, due to the longer incubation the level of observed DNA damage significantly has lowered. Other studies confirm that fluoxetine blocks the cell cycle in the G0/G1 phase due to a disturbance of the skp2-CKS1 complex, which is required for the proper course of the cell cycle [41]. The arrest can also be correlated with a reduction of cyclin A protein expression, responsible for regulating cell division $[42,43]$.

Once we had identified that ADs possessed activity to disturb the balance in the antioxidant systems, impair ATP production, cell cycle deregulation as well as H2AX phosphorylation and $\mathrm{MN}$ formation, we turned our attention 


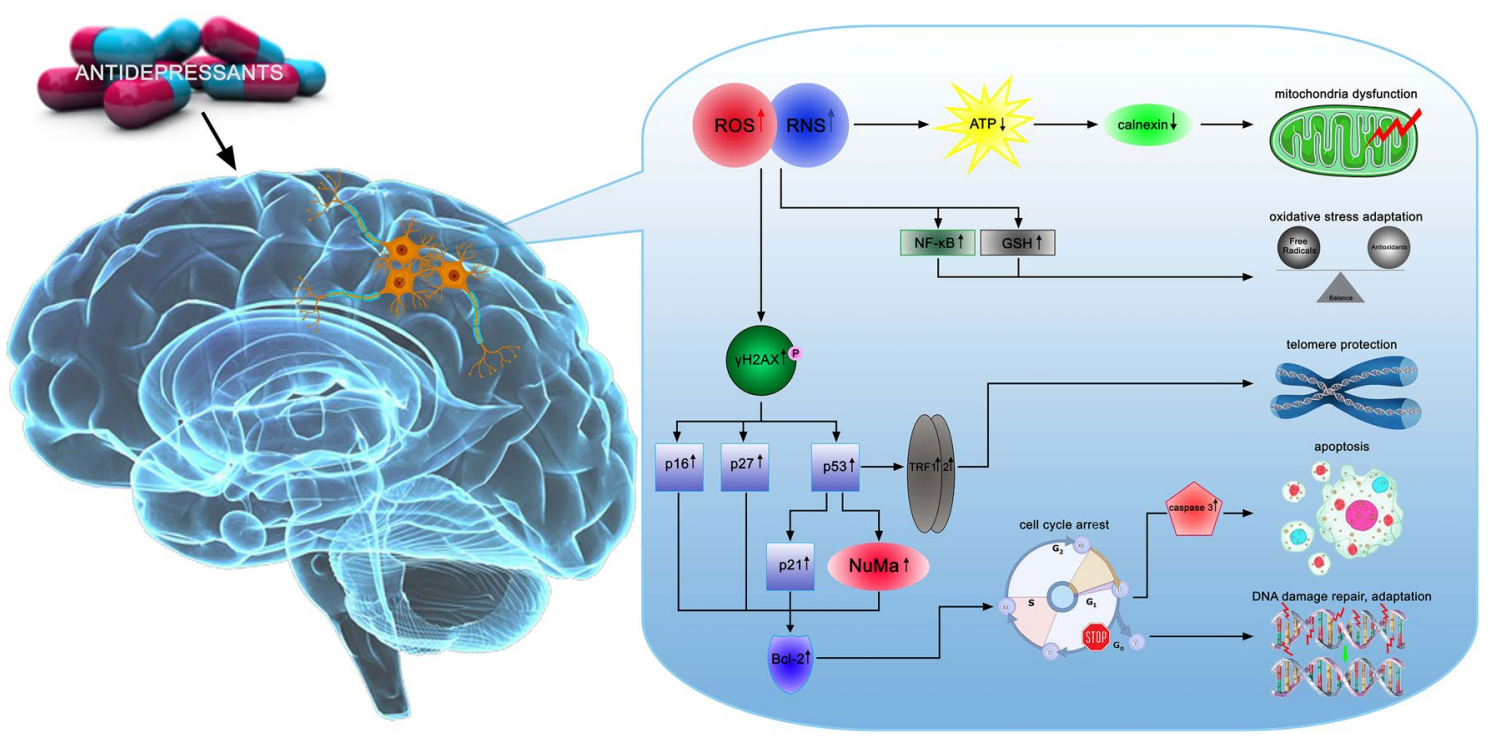

Fig. 5 Proposed molecular mechanisms underlying the complex and multi-stage processes of hippocampal cell response to antidepressants

to understanding their mechanism of action. We noted a slight but not significant decrease in phospho-NF- $\mathrm{BB}$ level in HT-22 cells. Other studies confirm that drugs cause a drop in NF- $\mathrm{KB}$ protein activity, which is closely correlated with a relatively low level of free oxygen radicals $[44,45]$. The first mechanistic explanation of observed events is the observed up-regulation in p16 and p27 protein pools. p27 protein regulates cell cycle arrest in G1/G0 phase and is responsible for induction of programmed cell death, therefore, we assume that fluoxetine, amitriptyline and imipramine alone in the studied concentration lead to increased apoptosis. At the same time, there was no activation of $\mathrm{p} 21$ and $\mathrm{p} 53$ dependent pathways. To be precise, the $\mathrm{p} 53$ protein may be responsible for the prolongation of the G1 phase, which allows the repair of DNA damage [46]. On the other hand, the p16 protein also controls the normal progression of the cell cycle. Moreover, p16 over-expression occurs when numerous DNA damage and replication errors appear, which results in the cell cycle arrest. Here, we observed increased expression of p16 protein after combined antidepressants treatment, which confirms the prolonged inhibition of the cell cycle in the G0/G1 phase to allow cells to repair the damage. Furthermore, a high expression of p16 can also suggest damage in telomere sections. In fact, we noted upregulation of both telomere maintenance proteins, TRF1 and TRF2 after $96 \mathrm{~h}$ treatment (AMI/IMI + FLU co-treatment). Further, it was hypothesized that ADs treatment increases apoptotic cell death via caspase-3 pathways activation in a concentration-dependent manner [5, 47, 48]. Noteworthy, in the present study, a slight increase in the caspase-3 expression level due to the ADs treatment was observed only after $48 \mathrm{~h}$ in cells treated with single antidepressants. This effect was not reported in cells treated with combination of antidepressants. This demonstrates that apoptosis is activated in the most fragile cells and is associated with dysfunction of adaptive mechanisms. In the regulation of the caspase function proapoptotic and antiapoptotic proteins from the Bcl-2 family are also involved. What's more, the neuroprotective properties of Bcl-2 protein are known $[49,50]$ but the evidence suggest that drugs in a concentration-related manner may be neuroprotective to hippocampal neurons [51]. Our data indicated an upregulation of Bcl-2 expression after $48 \mathrm{~h}$. It seems that the use of antidepressants changes the level of Bcl-2 probably associated with the survival of neurons. Thus, in this study the reduction of cell number observed in cells treated with single antidepressants results rather from the proliferation inhibition rather than apoptosis initiation. On the other hand, acceleration of proliferation observed in cells co-treated with two antidepressants results from adaptation of effective adaptation and repair mechanisms.

Mitochondrial ROS production is often found to increase with ER stress [52]. Based on these findings it remains to be determined how the antidepressants may affect calnexin, protein involved in apoptosis triggered by endoplasmic reticulum stress [53] and NuMa involved in major cellular events such as DNA damage response, apoptosis and p53-mediated growth-arrest [54]. Indeed, we observed upregulated synthesis of NuMa protein only after $96 \mathrm{~h}$ exposure in cells treated with combination of antidepressants. We suppose that this protein is involved in long-term adaptation and p16-dependent cell cycle arrest but at the same time independent of p53. In turn, we noted down-regulation of 
calnexin which once again proves the positive action of the repair mechanisms activation (Fig. 5).

In conclusion, we provide for the first time evidence that co-treatment with amitriptyline/imipramine + fluoxetine initiates in cells adaptation mechanisms associated with TRF1/TRF2 proteins which adjust cells to stress and finally exerts less genotoxic events than in cells treated with single antidepressants.

Acknowledgements This work was supported by the Polish National Science Center [Preludium No. UMO-2014/15/N/NZ7/04097]. Z. Chelminiak, M. Cuprys, J. Fraczek are students of Biotechnology at University of Rzeszow, Poland.

Author contributions PS: conceived of the presented idea, designed and performed the experiments, analyzed the data, carried out data interpretation, designed the figures, wrote the paper; OK: performed the experiments, analyzed the data, carried out data interpretation; JM: provided critical feedback, performed the experiments, analyzed the data, carried out data interpretation; JB, ZC, MC, JF, ATL: performed the experiments; MK: conceived and designed the experiments, supervised the work. All authors read and approved the final version of this manuscript.

\section{Compliance with ethical standards}

Conflict of interest The authors declare that they have no conflict of interest.

Open Access This article is distributed under the terms of the Creative Commons Attribution 4.0 International License (http://creativeco mmons.org/licenses/by/4.0/), which permits unrestricted use, distribution, and reproduction in any medium, provided you give appropriate credit to the original author(s) and the source, provide a link to the Creative Commons license, and indicate if changes were made.

\section{References}

1. Sadat Z, Abedzadeh-Kalahroudi M, Kafaei Atrian M, Karimian Z, Sooki Z (2014) The impact of postpartum depression on quality of life in women after child's birth. Iran Red Crescent Med J 16(2):e14995

2. Brenes GA (2007) Anxiety, depression, and quality of life in primary care patients. Prim Care Companion J Clin Psychiatry 9(6):437-443

3. Romao AP, Gorayeb R, Romao GS, Poli-Neto OB, dos Reis FJ, Rosa-e-Silva JC, Nogueira AA (2009) High levels of anxiety and depression have a negative effect on quality of life of women with chronic pelvic pain. Int J Clin Pract 63(5):707-711

4. Cobanoglu H, Coskun M, Cayir A (2018) In vitro genotoxic and cytotoxic effects of doxepin and escitalopram on human peripheral lymphocytes. Drug Chem Toxicol 41(2):238-244

5. Levkovitz Y, Gil-Ad I, Zeldich E, Dayag M, Weizman A (2005) Differential induction of apoptosis by antidepressants in glioma and neuroblastoma cell lines: evidence for p-c-Jun, cytochrome c, and caspase-3 involvement. J Mol Neurosci 27(1):29-42

6. Racagni G, Popoli M (2008) Cellular and molecular mechanisms in the long-term action of antidepressants. Dialogues Clin Neurosci 10(4):385-400
7. Lang UE, Borgwardt S (2013) Molecular mechanisms of depression: perspectives on new treatment strategies. Cell Physiol Biochem 31(6):761-777

8. Thomas AM, Duman RS (2017) Novel rapid-acting antidepressants: molecular and cellular signaling mechanisms. Neuronal Signal. https://doi.org/10.1042/NS20170010

9. Moret C (2005) Combination/augmentation strategies for improving the treatment of depression. Neuropsychiatr Dis Treat 1(4):301-309

10. Si T, Wang P (2014) When is antidepressant polypharmacy appropriate in the treatment of depression? Shanghai Arch Psychiatry 26(6):357-359

11. Dunner DL (2014) Combining antidepressants. Shanghai Arch Psychiatry 26(6):363-364

12. Preskorn SH, Baker B (1997) Fatality associated with combined fluoxetine-amitriptyline therapy. JAMA 277(21):1682

13. Krymchantowski AV, Silva MT, Barbosa JS, Alves LA (2002) Amitriptyline versus amitriptyline combined with fluoxetine in the preventative treatment of transformed migraine: a double-blind study. Headache 42(6):510-514

14. Nelson JC, Mazure CM, Bowers MB Jr, Jatlow PI (1991) A preliminary, open study of the combination of fluoxetine and desipramine for rapid treatment of major depression. Arch Gen Psychiatry 48(4):303-307

15. Keks NA, Burrows GD, Copolov DL, Newton R, Paoletti N, Schweitzer I, Tiller J (2007) Beyond the evidence: is there a place for antidepressant combinations in the pharmacotherapy of depression? Med J Aust 186(3):142-144

16. Benfield P, Heel RC, Lewis SP (1986) Fluoxetine. A review of its pharmacodynamic and pharmacokinetic properties, and therapeutic efficacy in depressive illness. Drugs 32(6):481-508

17. Ziegler VE, Clayton PJ, Biggs JT (1977) A comparison study of amitriptyline and nortriptyline with plasma levels. Arch Gen Psychiatry 34(5):607-612

18. Zarei G, Reisi P, Alaei H, Javanmard SH (2014) Effects of amitriptyline and fluoxetine on synaptic plasticity in the dentate gyrus of hippocampal formation in rats. Adv Biomed Res 3:199

19. Elmorsy E, Al-Ghafari A, Almutairi FM, Aggour AM, Carter WG (2017) Antidepressants are cytotoxic to rat primary blood brain barrier endothelial cells at high therapeutic concentrations. Toxicol In Vitro 44:154-163

20. Hassanane MS, Hafiz N, Radwan W, El-Ghor AA (2012) Genotoxic evaluation for the tricyclic antidepressant drug, amitriptyline. Drug Chem Toxicol 35(4):450-455

21. Needham BL, Mezuk B, Bareis N, Lin J, Blackburn EH, Epel ES (2015) Depression, anxiety and telomere length in young adults: evidence from the National Health and Nutrition Examination Survey. Mol Psychiatry 20(4):520-528

22. Solek P, Majchrowicz L, Koziorowski M (2018) Aloe arborescens juice prevents EMF-induced oxidative stress and thus protects from pathophysiology in the male reproductive system in vitro. Environ Res 166:141-149

23. Moreno-Fernandez AM, Cordero MD, de Miguel M, DelgadoRufino MD, Sanchez-Alcazar JA, Navas P (2008) Cytotoxic effects of amitriptyline in human fibroblasts. Toxicology 243(1-2):51-58

24. Pula G, Pistilli A, Montagnoli C, Stabile AM, Rambotti MG, Rende M (2013) The tricyclic antidepressant amitriptyline is cytotoxic to HTB114 human leiomyosarcoma and induces p75(NTR)dependent apoptosis. Anticancer Drugs 24(9):899-910

25. Farrelly LA, Savage NT, O'Callaghan C, Toulouse A, YilmazerHanke DM (2013) Therapeutic concentrations of valproate but not amitriptyline increase neuropeptide Y (NPY) expression in the human SH-SY5Y neuroblastoma cell line. Regul Pept 186:123-130

26. Jahchan NS, Dudley JT, Mazur PK, Flores N, Yang D, Palmerton A, Zmoos AF, Vaka D, Tran KQ, Zhou M, Krasinska K, Riess JW, 
Neal JW, Khatri P, Park KS, Butte AJ, Sage J (2013) A drug repositioning approach identifies tricyclic antidepressants as inhibitors of small cell lung cancer and other neuroendocrine tumors. Cancer Discov 3(12):1364-1377

27. Cabras S, Saba F, Reali C, Scorciapino ML, Sirigu A, Talani G, Biggio G, Sogos V (2010) Antidepressant imipramine induces human astrocytes to differentiate into cells with neuronal phenotype. Int J Neuropsychopharmacol 13(5):603-615

28. Klingenberg M, Becker J, Eberth S, Kube D, Wilting J (2014) The NADPH oxidase inhibitor imipramine-blue in the treatment of Burkitt lymphoma. Mol Cancer Ther 13(4):833-841

29. Lobo V, Patil A, Phatak A, Chandra N (2010) Free radicals, antioxidants and functional foods: Impact on human health. Pharmacogn $\operatorname{Rev} 4(8): 118-126$

30. Kolla N, Wei Z, Richardson JS, Li XM (2005) Amitriptyline and fluoxetine protect PC12 cells from cell death induced by hydrogen peroxide. J Psychiatry Neurosci 30(3):196-201

31. Herbet M, Gawronska-Grzywacz M, Jagiello-Wojtowicz E (2015) Evaluation of selected biochemical parameters of oxidative stress in rats pretreated with Rosuvastatin and Fluoxetine. Acta Poloniae Pharm 72(2):261-265

32. Herbet M, Gawronska-Grzywacz M, Izdebska M, PiatkowskaChmiel I, Jagiello-Wojtowicz E (2016) Impact of combined treatment with rosuvastatin and antidepressants on liver and kidney function in rats. Exp Ther Med 11(4):1459-1464

33. Maruta S, Suzuki E, Yokoyama M, Sato T, Inada K, Watanabe S, Miyaoka H (2005) Effects of intraperitoneally injected lithium, imipramine and diazepam on nitrate levels in rat amygdala. Psychiatry Clin Neurosci 59(3):358-361

34. Taziki S, Sattari MR, Dastmalchi S, Eghbal MA (2015) Cytoprotective effects of melatonin against amitriptyline-induced toxicity in isolated rat hepatocytes. Adv Pharm Bull 5(3):329-334

35. Duda W, Curzytek K, Kubera M, Iciek M, Kowalczyk-Pachel D, Bilska-Wilkosz A, Lorenc-Koci E, Leskiewicz M, Basta-Kaim A, Budziszewska B, Regulska M, Slusarczyk J, Gruca P, Papp M, Maes M, Lason W, Antkiewicz-Michaluk L (2016) The effect of chronic mild stress and imipramine on the markers of oxidative stress and antioxidant system in rat liver. Neurotox Res 30(2):173 $-184$

36. Bishop GM, Dringen R, Robinson SR (2007) Zinc stimulates the production of toxic reactive oxygen species (ROS) and inhibits glutathione reductase in astrocytes. Free Radic Biol Med 42(8):1222-1230

37. Lauterbach EC, Fontenelle LF, Teixeira AL (2012) The neuroprotective disease-modifying potential of psychotropics in Parkinson's disease. Parkinsons Dis. https://doi.org/10.1155/2012/75354 8

38. Charles E, Hammadi M, Kischel P, Delcroix V, Demaurex N, Castelbou C, Vacher AM, Devin A, Ducret T, Nunes P, Vacher P (2017) The antidepressant fluoxetine induces necrosis by energy depletion and mitochondrial calcium overload. Oncotarget 8(2):3181-3196

39. Elmorsy E, Al-Ghafari A, Helaly ANM, Hisab AS, Oehrle B, Smith PA (2017) Editor's highlight: therapeutic concentrations of antidepressants inhibit pancreatic beta-cell function via mitochondrial complex inhibition. Toxicol Sci 158(2) 286-301

40. Pellegata NS, Antoniono RJ, Redpath JL, Stanbridge EJ (1996) DNA damage and p53-mediated cell cycle arrest: a reevaluation. Proc Natl Acad Sci USA 93(26):15209-15214
41. Stopper H, Garcia SB, Waaga-Gasser AM, Kannen V (2014) Antidepressant fluoxetine and its potential against colon tumors. World J Gastrointest Oncol 6(1):11-21

42. Kannen V, Garcia SB, Silva WA Jr, Gasser M, Monch R, Alho EJ, Heinsen H, Scholz CJ, Friedrich M, Heinze KG, Waaga-Gasser AM, Stopper H (2015) Oncostatic effects of fluoxetine in experimental colon cancer models. Cell Signal 27(9):1781-1788

43. Krishnan A, Hariharan R, Nair SA, Pillai MR (2008) Fluoxetine mediates $\mathrm{G} 0 / \mathrm{G} 1$ arrest by inducing functional inhibition of cyclin dependent kinase subunit (CKS)1. Biochem Pharmacol 75(10):1924-1934

44. Morioka N, Suekama K, Zhang FF, Kajitani N, HisaokaNakashima K, Takebayashi M, Nakata Y (2014) Amitriptyline up-regulates connexin43-gap junction in rat cultured cortical astrocytes via activation of the $\mathrm{p} 38$ and c-Fos/AP-1 signalling pathway. Br J Pharmacol 171(11):2854-2867

45. Lee YH, Kim SH, Kim Y, Lim Y, Ha K, Shin SY (2012) Inhibitory effect of the antidepressant imipramine on NF-kappaBdependent CXCL1 expression in TNFalpha-exposed astrocytes. Int Immunopharmacol 12(4):547-555

46. Schmitt CA, Fridman JS, Yang M, Baranov E, Hoffman RM, Lowe SW (2002) Dissecting p53 tumor suppressor functions in vivo. Cancer Cell 1(3):289-298

47. Xia Z, Bergstrand A, DePierre JW, Nassberger L (1999) The antidepressants imipramine, clomipramine, and citalopram induce apoptosis in human acute myeloid leukemia HL-60 cells via caspase-3 activation. J Biochem Mol Toxicol 13(6):338-347

48. Abdel-Razaq W, Kendall DA, Bates TE (2011) The effects of antidepressants on mitochondrial function in a model cell system and isolated mitochondria. Neurochem Res 36(2):327-338

49. Howard S, Bottino C, Brooke S, Cheng E, Giffard RG, Sapolsky R (2002) Neuroprotective effects of bcl-2 overexpression in hippocampal cultures: interactions with pathways of oxidative damage. J Neurochem 83(4):914-923

50. Ouyang YB, Giffard RG (2004) Cellular neuroprotective mechanisms in cerebral ischemia: Bcl-2 family proteins and protection of mitochondrial function. Cell Calcium 36(3-4):303-311

51. Xu H, Steven Richardson J, Li XM (2003) Dose-related effects of chronic antidepressants on neuroprotective proteins BDNF, Bcl-2 and $\mathrm{Cu} / \mathrm{Zn}-\mathrm{SOD}$ in rat hippocampus. Neuropsychopharmacology 28(1):53-62

52. Zeeshan HM, Lee GH, Kim HR, Chae HJ (2016) Endoplasmic reticulum stress and associated ROS. Int J Mol Sci 17(3):327

53. Guerin R, Arseneault G, Dumont S, Rokeach LA (2008) Calnexin is involved in apoptosis induced by endoplasmic reticulum stress in the fission yeast. Mol Biol Cell 19(10):4404-4420

54. Jayaraman S, Chittiboyina S, Bai Y, Abad PC, Vidi PA, Stauffacher CV, Lelievre SA (2017) The nuclear mitotic apparatus protein NuMA controls rDNA transcription and mediates the nucleolar stress response in a p53-independent manner. Nucleic Acids Res 45(20):11725-11742

Publisher's Note Springer Nature remains neutral with regard to jurisdictional claims in published maps and institutional affiliations. 